\title{
Artelogie
}

Recherche sur les arts, le patrimoine et la littérature de l'Amérique latine

2 | 2012

Mexique : espace urbain et résistances artistiques et littéraires face à la « ville générique »

\section{Ramón López Velarde: la zozobra de un espíritu en la ciudad de México}

Sergio Miranda Pacheco

\author{
(2) OpenEdition \\ Journals \\ Edición electrónica \\ URL: https://journals.openedition.org/artelogie/7677 \\ DOI: 10.4000/artelogie.7677 \\ ISSN: 2115-6395 \\ Editor \\ Association ESCAL
}

Referencia electrónica

Sergio Miranda Pacheco, «Ramón López Velarde: la zozobra de un espíritu en la ciudad de México», Artelogie [En línea], 2 | 2012, Publicado el 21 enero 2012, consultado el 07 enero 2022. URL: http:// journals.openedition.org/artelogie/7677 ; DOI: https://doi.org/10.4000/artelogie.7677

Este documento fue generado automáticamente el 7 enero 2022.

Association ESCAL 


\title{
Ramón López Velarde: la zozobra de un espíritu en la ciudad de México
}

\author{
Sergio Miranda Pacheco
}

Contra mi voluntad emprendí el temido regreso al terruño. Después de siete años volví a recorrer las leguas y leguas de alcaparras, hasta alcanzar el puente pegado a mi lugar, el puente sin arcos, el dramático puente sin concluir a cuya vista se detienen los carruajes si la henchida cólera del río los excomulga. Trunco dolor del puente, cuya inutilidad apenas sirve a las golondrinas, estas

amantes comisionadas que se esforzarán en acompañarme, volando al ras de la banqueta. Se me destina, en la casona, la sala de la derecha. Fantasmas, fantasmas, fantasmas. A las diez de la noche, logro escaparme. En un cielo turquí, el relámpago flagela edredones de nube. La ciudad jerezana me tienta con un mixto halago de fósil y de miniatura. Divago por ella en un traspiés ideal

y no soy más que una bestia deshabitada que cruza por un pueblo ficticio.

"En el solar" (c.1909) Ramón López Velarde Mejor será no regresar al pueblo, al edén subvertido que se calla en la mutilación de la metralla.

Hasta los fresnos mancos, los dignatarios de cúpula oronda, han de rodar las quejas de la torre acribillada en los vientos de fronda. Y la fusilería grabó en la cal de todas las paredes 


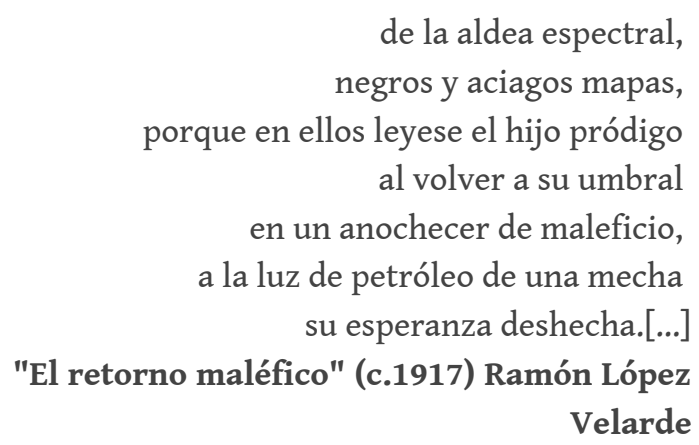

1 A su contacto con la vida en las ciudades mexicanas, en especial de la ciudad de México, la sensibilidad poética de Ramón López Velarde se nutrió de nuevas experiencias que traduciría en la elaboración de una obra sin igual, tanto por sus contenidos como por sus formas. El rasgo más destacado de su poesía en la que se ocupa de la ciudad confronta el bullicio y novedad de la vida urbana, con la paz edénica de la vida en provincia. Así, la ciudad es a veces lamento y gozo, en otras un eco sordo y un himno alegre, en otras esperanza y perdición. ¿Qué explica esta tensión moral con que el poeta se refiere a la ciudad?

2 El presente ensayo se propone demostrar que aunque es posible hallar en la poesía de López Velarde cierta caracterización de la vida en la capital mexicana, ésta no es la de un cronista o la de un expectador más de la ciudad, sino la de quien, como él, buscó expresar el estado particular de su alma atropellada y embelesada por una ciudad cuya forma de vida, como a tantos otros hombres de ayer y siempre, le atrajo poderosamente como un imán. En este sentido, su poesía no retrata aisladamente costumbres, sino que éstas tienen que ver con sus sentimientos y deseos más profundos, alimentados tiempo atrás en la paz y en el silencio provincianos, los cuales hallaron en la ciudad un lugar para el esparcimiento de su innato sensualismo y para el remordimiento por acceder a éste. Así, pues, la tensión moral y poética con que López Velarde habla de la ciudad es la prueba más palpable de que el hecho fundamental de la vida moderna, tal como él la experimentó, es la contradicción que la sustenta y que la ciudad, como escenario y fuente de esa contradicción, provocaba zozobra en aquellos que, como él, llegaron a ella buscando alimentar un cuerpo y una pasión y se encontraron con que sus instintos podían desbocarse en todas las direcciones posibles.

3 A mi juicio dichas coordenadas son: la transformación política, social y material que vivió México desde fines del siglo XIX bajo el régimen de Porfirio Díaz y los primeros gobiernos de la Revolución; la sensibilidad y el lenguaje poéticos de los modernistas con que acrisolaron toda experiencia de lo efímero y lo cambiante de la vida moderna hasta arrancarle su estremecimiento esencial y único; ${ }^{1} \mathrm{y}$, por último, la oriundez provinciana de López Velarde que imprimió a su alma una singular sensibilidad que cobró matices extraordinarios a su contacto con la vida y costumbres metrópolitanas de la ciudad de México en los comienzos del siglo XX. Para dar fe de estas influencias en la obra velardiana nos hemos valido de las ideas que sobre las relaciones entre la vida moderna de las ciudades y la literatura plantea Marshall Berman, ${ }^{2}$ de textos de historia de la ciudad de México, de textos de crítica sobre su obra y, principalmente, del análisis de su poesía, más que de su prosa, en la que son visibles sus percepciones de la vida en las ciudades mexicanas de comienzos del siglo XX. 


\section{La ciudad moderna y la literatura}

4 Si aceptamos la idea de Marshall Berman de que ser modernos es encontrarnos en un entorno que nos promete aventuras, poder, alegría, crecimiento, transformación de nosotros y del mundo y que, al mismo tiempo, amenaza con destruir todo lo que tenemos, todo lo que sabemos, todo lo que somos, ${ }^{3}$ podríamos convenir en que la experiencia fundamental de la modernidad que compartimos hoy millones de personas en todo el planeta es la ciudad.

5 En la ciudad se conjugan todas las fuentes de la modernidad: los avances y descubrimientos de la ciencia, la industrialización de la producción, la explosión demográfica, la expansión urbana, el poder omnipresente del Estado, la lluvia de los medios de comunicación de masas y el creciente poder del mercado capitalista. ${ }^{4}$ Gracias a su poder magnético y centralizador, a través de la historia la ciudad ha sido cuna de los grandes descubrimientos científicos, escenario para las atrocidades a que algunos de éstos han dado lugar, para la guerra y la paz, para la riqueza y la pobreza, para la vida y la muerte, para la soledad y la convivencia, e inspiración de artistas, presagio del desenlace del hombre, recuerdo de la esperanza y anhelo del porvenir, refugio de lo sagrado y de lo profano, imagen del futuro y del pasado, y, por antonomasia, hogar del hombre moderno.

6 Fue en el siglo XIX cuando, bajo el impulso de la industrialización, la urbanización, la explosión demográfica, el surgimiento de los estados nación, el ensanchamiento de los mercados, y de otros grandes procesos que marcaron al mundo entero, las ciudades y la vida urbana generaron la atmósfera en que nació la sensibilidad moderna, una atmósfera de agitación y turbulencia, vértigo y embriaguez psíquicos, de extensión de las posibilidades de la experiencia y de destrucción de las barreras morales y los vínculos personales, de expansión y desarreglo de la personalidad, y de fantasmas en las calles y en el alma.

7 El progreso científico y material alcanzado a lo largo del siglo XIX dio a lugar a que la literatura europea, primero, y la hispanoamericana, después, dejaran de interesarse exclusivamente en componer una obra estéticamente valiosa para dar un mayor peso al cuestionamiento de los supuestos progresos de la sociedad moderna. Así, el Modernismo nació como una corriente literaria que buscó crear un lenguaje y una poética para expresar los nuevos contenidos y las nuevas percepciones del alma humana producidos por los cambios registrados en las formas de pensar y de vivir. De hecho, como afirma José E. Pacheco, 'en su connotación más inmediata el modernismo es la literatura que corresponde al mundo moderno, a las sociedades transformadas por las revoluciones social, industrial, científica y tecnológica'. ${ }^{5}$ Por eso el movimiento modernista comenzó simultáneamente, primero, en la poesía y en la novela europeas hacia 1860 y después, luego de que adquirió las primeras bases de su modernización, en Hispanoamérica a fines del siglo XIX. ${ }^{6}$

8 A la vida en las ciudades, como productos y productoras de la modernidad, y como extensiones de la sensibilidad humana, voltearon sus ojos poetas y escritores tratando de descifrar en su rostro el de ellos, de denunciar y curar sus heridas, de hacer himnos a su cosmopolitismo y a la miseria de la vida urbana. Asi, por ejemplo, París tuvo, entre otros, a Baudelaire y a Rimbaud, San Petersburgo a Pushkin y a Dostoyevski, Lisboa a Pessoa y la ciudad de México a López Velarde. Todos ellos compartieron una conciencia 
crítica de su tiempo que les llevó a atacar apasionadamente su entorno, aunque sin dejar de ser sensibles a las posibilidades que éste les ofrecía.

Por su parte, el modernismo hispanoamericano logró su originalidad "en un momento de circulación universal de ideas y de estilos". 7 Sus poetas más representativos intentaron "captar la vida y el ambiente de los pueblos de América, traducir sus inquietudes, sus ideales y sus esperanzas [...] sin abdicar por ello de su rasgo característico principal: trabajar el lenguaje con arte". ${ }^{8}$ De este modo, en el modernismo hispanoamericano "se une la solitaria rebelión romántica, la música de la palabra aprendida en los simbolistas y la precisión plástica tomada de los parnasianos". ${ }^{9}$ Pero más concretamente, 'los modernistas [...] arrastraron consigo el bagaje sentimental de Bécquer, Novalis, Lamartine, Víctor Hugo y demás románticos. La atmósfera delicuescente, el claroscuro, los acentos trágicos, la concepción de lo efímero, son en mayor grado caracteres comunes a la poesía de José Asunción Silva, Gutiérrez Najera, Julian de Casal, Enrique González Martínez, Rubén Darío, y aun a la de López Velarde, Cesar Vallejo y Pablo Neruda, considerados como poetas de vanguardia o posmodernistas'. ${ }^{10}$

\section{La modernidad de la ciudad de México}

10 La ciudad de México experimentó amplias y profundas transformaciones en el último tercio del siglo XIX y las primeras décadas del siguiente a causa de los cambios que en los órdenes político y económico había implementado el régimen de Porfirio Díaz, algunos de los cuales fueron continuados por los gobiernos posrevolucionarios. La principal consecuencia de estos cambios fue que la capital mexicana recuperó su primacía como principal centro urbano y económico del país.

11 Entre los factores que contribuyeron al robustecimiento urbano y metropolitano de la ciudad, pueden contarse el rápido desarrollo ferrocarrilero iniciado en 1880 con la concesión otorgada a empresarios norteamericanos para construir las principales líneas troncales que la conectarían con la frontera norte, y que la convertirían en la localidad urbana mejor comunicada con las principales ciudades y con ello en el centro comercial y administrativo más importante de todo el país. ${ }^{11}$ De igual manera, la introducción de energía eléctrica para sustituir la fuerza motriz hidráulica, favoreció la concentración de la naciente producción industrial en la capital al otorgar a la industria una mayor movilidad espacial y una diversificación productiva que no habían permitido la dependencia de fuentes energéticas hidráulicas..$^{12}$ Así, el capital nacional y extranjero volcaron sus inversiones en el comercio y la industria del país y de la capital, protegidos por las concesiones y subsidios del régimen porfirista, a la vez que éste hacia lo propio en materia de infraestructura, pues las cifras de los recursos que invirtió el estado en este rubro no dejan lugar a dudas sobre la importancia estratégica que tenía la ciudad de México en la política económica del gobierno de Díaz. ${ }^{13}$

12 En Novedad de la Patria (1921), López Velarde sopesó los logros del porfiriato y señaló que, gracias a la paz con que lo había cubierto, México obtuvo un descanso material que '[..] coadyuvó a la idea de una patria pomposa, multimillonaria, honorable en el presente y epopéyica en el pasado [..] menos externa, más modesta y probablemente más preciosa'. Los adjetivos que empleó entonces López Velarde para caracterizar a la patria (pomposa, multimillonaria, honorable y epopéyica), seguramente le fueron inspirados por la ciudad de México, la cual en la primera década del siglo XX se había vestido con nuevas colonias, avenidas, servicios, monumentos y una variedad de 
actividades que le imprimían un carácter moderno y cosmopolita, no obstante que también, como escribió López Velarde, se resumían en ella las contradicciones del país diseminadas por todo el territorio nacional.

En efecto, la importancia que tenía la ciudad de México, como centro político y cultural, se hizo más evidente con el crecimiento económico y la centralización política que caracterizaron al régimen de Díaz y que continuaron los gobiernos posrevolucionarios. Así, aunque la posibilidad de transformación de la fisonomía urbana de la ciudad se inició desde los años de la Reforma con la política de desamortización que fracturó la ciudad de corte colonial y ofreció al mercado inmobiliario nuevos terrenos, no fue sino en el apogeo del porfiriato "que el torbellino del progreso envolvió a la ciudad de México" y surgió un ambiente de optimismo en el que florecieron varios aspectos de las artes y la cultura, entre las cuales destacaron la arquitectura, la publicidad y el consumo. $^{14}$

Las élites edificaron sus casas inspiradas en los estilos en boga, diferentes a las viejas construcciones coloniales: villas a la italiana, 'chateaux' renacentistas, 'maisons' griegas, 'cottages' ingleses, y 'bastides' marsellesas. Por ejemplo, a comienzos de 1907 José Juan Tablada retrató la fiebre constructora que contagiaba a la ciudad de México así:

Por doquiera se miran escombros, caen las viejas mansiones con pesar de poetas y arqueólogos; pero México le da a su rostro el sentimiento de su alma civilizada y moderna. De esos escombros, de esas ruinas surge poco a poco la ciudad nueva. Los gestos coloniales torvos, ascéticos y llenos de hastío se van desvaneciendo sobre su rostro que asume la serenidad y la fuerza de un sólido progreso ${ }^{15}$

Para el año de 1910 las colonias San Cosme, Juárez, Condesa y Roma, de reciente creación, además de los fraccionamientos de los alrededores del Paseo de la Reforma y de Bucareli, detentaban en sus calles y casas -estilo parisino, flamenco, neoyorquino y bostoniano- la porción moderna de la ciudad capital donde vivía la clase pudiente, la cual contrastaba con la porción vieja de la ciudad, ubicada en el centro, de origen colonial donde tenían sus insanas viviendas los habitantes menos afortunados.

Para darnos una idea de este acelerado crecimiento la ciudad bastaría con señalar que de 1901 a 1926 se fundaron 64 colonias por todo el territorio del Distrito Federal, mientras que entre 1850 y 1900 apenas se habían establecido 54, es decir, que en medio siglo se fundaron menos colonias que en un cuarto de siglo. ${ }^{16}$ De otro lado, los sistemas de transporte tradicionales comenzaron a ser sustituidos por el automóvil y los tranvías eléctricos. El telégrafo, cuyas primeras líneas se instalaron a mitad del siglo XIX, extendió sus redes de comunicación a casi todo el país, lo mismo que el ferrocarril que hizo de la ciudad punto de paso obligado y principal centro del comercio y de la transacción internacional para todo el país. Mientras que el uso del teléfono, que llegó a la ciudad a fines del siglo pasado, se extendía cada vez más entre la población. ${ }^{17}$

17 Pero los cambios que trajo consigo la modernidad a la ciudad de México no sólo se registraron en su ensanchamiento físico y en su arquitectura moderna, sino también en los hábitos y forma de vida de los capitalinos.

18 Desde comienzos del siglo XX, sobre los muros de las calles de la ciudad, en las páginas de revistas y periódicos, o en escaparates de tiendas y establecimientos comerciales de todo tipo, imágenes publicitarias de diversa índole impelían a los habitantes citadinos a comprar, hacer, comer, tomar, leer, untarse, probar, oler, escuchar, mirar, visitar, conocer, palpar, sentir, e imaginar una cauda de bienes y satisfacciones proveídas por 
los múltiples productos que ofrecía la vida moderna a aquel deseoso de experimentar y ensanchar su ser individual para distinguirse de la muchedumbre. ${ }^{18}$

Algunos de estos lugares de placer y consumo en la ciudad fueron casinos y clubes como el Casino Nacional, el Jockey Club, el Casino Español, el Casino Francés y el Club Nacional de México Parque Lira. El folleto publicitario de este último lugar, establecido en lo que fuera "casa solariega de la Condesa de Rábago y del Conde de la Cortina, conocida por Quinta Barrón", en Tacubaya, proclamaba que se trataba de una "institución de prestigio", a la que acudían solamente los mejores elementos de la sociedad. ${ }^{19}$

Hubo otros lugares donde otras versiones de la modernidad, menos exclusiva, recibían los favores diarios de sus adeptos. Cafés, como el Colón, que frecuentaba López Velarde, y cines, cantinas, teatros y prostíbulos, a los cuales, según Sheridan, también era adicto el poeta, como el del callejón de la Condesa, se propagaron por todos los rumbos de la ciudad. Una ciudad que "acogía sonrientemente a todos los que llegaban, pero no daba sus favores a nadie", ${ }^{20}$ una ciudad que no obstante que sus calles estaban pobladas de mendigos, "de niños que dormían en el asfalto, de gentes deformes en los atrios de las iglesias", "era sensual [...] estaba llena de esos momentos revolucionarios, y del deseo de los cuerpos extraños"

\section{La experiencia de la ciudad en López Velarde}

21 La vida Ramón López Velarde (1888-1921) transcurrió en esta época de transición para el México, pues a lo largo de ella -que fue muy corta- pudo atestiguar los logros y fracasos del Porfiriato, así como la crudeza de la Revolución y las contradicciones de sus primeros gobiernos.

Prácticamente su infancia y juventud las pasó en provincia. Primero en su tierra natal, Zacatecas, hasta la mitad de 1902. Luego se trasladó a Aguascalientes donde permaneció hasta 1907, para establecerse después en San Luis Potosí de donde salió en 1912 para dirigirse por primera vez a la ciudad de México. Durante este período, que abarca casi 24 años, la educación, valores y moral religiosa de López Velarde ya tenían una madurez que se reflejaría en los poemas que escribió entonces.

Si echamos un vistazo a su obra poética tratando de encontrar en ella la voz que pudiera caracterizar la experiencia de la ciudad que obtuvo durante estos años, podemos decir que ésta se nutrió no sólo de la modernidad de la ciudad de México, sino también de la de aquellas otras ciudades que él conoció antes de venir a vivir a la capital definitivamente a partir de 1914: Zacatecas, Aguascalientes y San Luis Potosí.

En términos generales, los que podríamos llamar poemas de su época precapitaliza aluden directa o indirectamente a la vida de las ciudades de provincia que conoció, y en ellos coloca a la ciudad como la antípoda de la vida provinciana. Así, por ejemplo, con el alma desolada por la indiferencia del siglo (Del Seminario, 1909), escribe en 1910 el poema $A$ una ausente seráfica, en el que compara a las ciudades con

[...] sitios vulgaresen que

en el ruido mundanal se asusta

el alma fidelísima,[...]'

sitios frente a los cuales añora

'[...] dulcemente los lugares

en donde imperas cual señora justa 
tu voz real y tu mirada augusta

que ungieron con su gracia mis pesares

En este poema la ciudad, o mejor dicho la vida en ella, le produce una melancolía que sólo puede ser curada en aquel lugar donde su amada posee 'raras virtudes milagrosas' y una 'amable modestia provinciana'. ${ }^{22}$

Este carácter maléfico de la ciudad y la benignidad de provincia y sus mujeres se repite en otros poemas. En A la gracia primitiva de las aldeanas, escrito cerca de 1910, habla de que las ciudades son 'flores de pecado' porque los hombres practican en ellas 'turbadores gozos' para satisfacer su hambre de amores y su sed de ensueño, ante lo cual él prefiere los 'hechizos provincianos' de las 'muchachas de los pueblos' y 'beber del agua contenida en el hueco que forman vuestras manos'. ${ }^{23}$

Esta obsesión por los gozos pecadores de las ciudades continua en el poema Cuaresmal, ${ }^{24}$ sin fecha, en el que opone el 'amor aventurero de cálidas mujeres, azafatas súbditas de la carne', a 'la frescura de [las] manos gratas' de su amada purísima Fuensanta, cuyas 'plantas no son hechas para los bailes frívolos del mundo', según nos dice en Poema de vejez y amor (c. 1909) 25 .

Incluso, en el poema Una viajera, de febrero de $1912,{ }^{26}$ llega a advertir a las provincianas que andan 'en metrópolis [...] en ruidoso paseo' que regresen a su pueblo 'para que no se manche [su alma, como se había manchado la de él] con el barro de ciudades impuras', pues los domingos en las ciudades capitales no ocurre lo que en los Domingos de provincia (c. 1908) ${ }^{27}$ donde '[...]al caer sobre el pueblo la noche ensoñadora, los amantes se miran con la mejor mirada'. los hombres que 'oyendo los poetas [sus] discursos sanos/para siempre se curan de males ciudadanos,/ y en la aldea la vida buenamente pasa'.

Estos poemas, escritos entre 1909 y 1912, resumen el estado del alma y las ideas que López Velarde profesaba en torno a las ciudades, pero más que a las ciudades, en torno a las formas de vida que en ella se daban y que llamaban poderosamente su atención porque de algún modo contradecían su temperamento religioso y le producían desolación espiritual. El hecho de que en sus poemas destaque la oposición de la liviandad, la impureza, y la indiferencia del amor de las mujeres de la ciudad, el ruido y bullicio de la misma con la bondad y la belleza ingenua de las aldeanas de provincia y la paz y el silencio que invaden a sus pueblos, nos hablan de esta búsqueda que hizo en la ciudad. Una búsqueda por saciar su sed de amor y encontrar paz para la ensoñación de su alma. Y aunque más tarde claudicó ante los 'turbadores gozos' de la ciudad de México su sed no se apagó.

1 En los poemas escritos a partir de 1915, cuando ya está instalado permanentemente en la ciudad de México, se notan ciertos cambios que apuntan hacia una integración en su alma de los descubrimientos hechos por él en su persona, ayudado por la vida cosmopolita que comenzó a llevar. Sin embargo, al mismo tiempo su alma parece más contrariada, enferma de amor y soledad, enferma de ansia de dicha absoluta. Así, por ejemplo, en este año, confiesa en La Tejedora que

divago entre quimeras difuntas y entre sueños nacientes, y propenso a un llanto sin motivo, voy, con el alma dispersa $[. . .]^{28}$

Parece como si en su interior hubieran ocurrido paralelamente el alumbramiento y la muerte de sensaciones y de sueños, de tal magnitud que, en El minuto cobarde, fechado 
el 12 de agosto de 1916, se 'acobarda' y juzga de algún modo su anterior vida austera y provinciana , pasada entre 'anticuados relojes de curato', lunas dormilonas y coquetas, un piano llorón, santos de piedra, cromos bobalicones, y canteras de monjil reposo, cosas todas ellas que retardaron indefinidamente, 'con intención pura', su 'primera amargura'. ${ }^{29}$ No obstante, al mismo tiempo clama 'a la justicia original de todas estas cosas'. Sin embargo, pese a su súplica interior por reencontrarse con su alma quebrada, en su

[...] pecho siguen germinando

las plantas venenosas, y mi violento espíritu se halla

nostálgico de sus jaculatorias y del pío metal de su

medalla.

La zozobra a la que había llegado su alma continúa ese mismo año, 1916. En Que sea para bien considera ya muerta su niñez, 'toda olorosa a sacristía'. En A la patrona de mi pueblo trata de redimir su alma que viene ya 'desde las tenebrosas anarquías del pensamiento y la conducta'.

34 En suma, en estos años, 1915-1921, ya había entregado su corazón a la búsqueda de 'arrogantes quimeras' (Humildemente, $\mathrm{s} / \mathrm{f}$ ) y estaba dedicado a profesar la moral de la simetría (Gaviota, c. 1920). Quimeras y simetría cuya libertad para buscarlas y profesarlas sólo pudo haberla encontrado en un ambiente propicio para ello: la ciudad moderna. La conciencia de este hecho está clara en el poema Mi villa, sin fecha, donde dice:

Si yo jamás hubiera salido de mi villa, con una santa esposa tendría el refrigerio

de conocer el mundo por un solo hemisferio.

Este poema nos ofrece una concepción dual de la ciudad. Por un lado, sugiere que la 'ciudad' permite conocer al mundo simétricamente, es decir, en su totalidad. Pero, por otro lado, este conocimiento adquirido exige una ardua y dolorosa tarea de construcción del equilibrio de la que el alma sale exhausta e insatisfecha, porque esa tarea, el equilibrio entre lo que es el mundo y los deseos del hombre. sólo se cumple cabalmente en la muerte. Por esta razón, conocer el mundo por un solo hemisferio con una santa esposa aldeana, es un descanso pero no un alivio para un alma erotizada y contagiada de absoluto como la de él.

Pero el conflicto entre sus valores y creencias religiosas y el vuelo de su espíritu erótico, que como nunca había alcanzado alturas insospechadas en la ciudad de México -gracias a que en ella vino a conocer la obra literaria de escritores europeos y españoles que se dedicaban a la introspección de sus almas-, no sólo se nutrió de este conocimiento y experiencia, sino también de la amargura que la Revolución causó a su pasado aldeano, a la ciudad de su infancia y de su primer amor.

Amargura y 'tristeza reaccionaria' que están presentes en su poema $E l$ retorno maléfico, sin fecha, en el que las balas subvirtieron el 'edén' aldeano en un infierno y destruyeron la esperanza de recuperar su infancia. Este anhelo de recuperar. el paraíso de paz y alegría que significaba para él la vida aldeana, lo alimentó hasta el fin de sus días. Así, en Las desterradas, fechado en 1917, reconoce en las provincianas de Morelia y Toluca, de Durango y de San Luis, que vienen a la ciudad a buscar la vida, al 'opíparo destino' y se deleita con su aroma de anís que invade a la metrópoli. En suma, podemos decir que la provincia para López Velarde significó el edén que perdió cuando salió de su villa para conocer el mundo. Las ciudades que conoció y 
donde vivió le hicieron ver 'lejos del terruño, la familia distante y en la hora gris del éxodo [...] que hay jornadas luctuosas y alegres en el mundo' (Noches de Hotel, s/f). El dolor de esta pérdida y de este descubrimiento, que también le causó gozo, fueron los elementos centrales de su conflicto urbano, a los que se añadían su anhelo religioso y su anhelo erótico. Quizás, gracias a que cuando vino a la ciudad de México ya 'tenía la ropa tendida' (Avenida Madero) pudo observar y vivir con más intensidad la novedad y contradicciones de la vida moderna y, por la misma razón, amar a la ciudad, respetarla y mirarla como pocos la han mirado' ${ }^{\prime 30}$.

Su alma sufrió porque no poseía lo bastante al mundo ${ }^{31}$ y porque no podía dominar el curso de su corriente en la que iba su propia vida. ${ }^{32}$ Morir en la ciudad, donde nunca vio colmados sus deseos, no fue, precisamente, uno de esos deseos. López Velarde hubiera preferido Humildemente que:

Cuando me sobrevenga

el cansancio del fin,

me iré, como la grulla

del refrán, a mi pueblo,

a arrodillarme entre

las rosas de la plaza,

los aros de los niños

y los flecos de seda de los tápalos.

\section{BIBLIOGRAFÍA}

BERMAN, Marshall, Todo lo sólido se desvanece en el aire. La experiencia de la modernidad, 2da. ed. México, Siglo XXI Editores, 1989.

BERRA STOPPA, Erika, La expansión de la ciudad de México y los conflictos urbanos, 2 vols, México, El Colegio de México, 1982. (Tesis Dr. en Historia).

FUENTE, Carmen de la, López Velarde: su mundo intelectual y afectivo, 2a. ed., México, Gobierno del Estado de Zacatecas/ UAZ/INBA, 1988.

GORTARI RABIELA, Hira de, '¿Un modelo de urbanización? La ciudad de México de finales del siglo XIX', en Secuencia, núm.8, México, Instituto de Investigaciones José Ma. Luis Mora, MayoAgosto 1987, pp. 42-52.

LIRA VAZQUEZ, Carlos, Para una historia de la arquitectura mexicana, México, UAM-Azcapotzalco/ Tilde, 1990.

LÓPEZ VELARDE, Ramón, El León y la Virgen, 2da. ed., pról. y sel. de Xavier Villaurrutia, México, UNAM, 1971. (Biblioteca del estudiante Universitario, 40)

LÓPEZ VELARDE, Ramón, La suave patria y otros poemas, prólogo de Octavio Paz, México, Fondo de Cultura Económica, 1987. (Colección Popular, 347)

LÓPEZ VELARDE, Ramón, Obras, 2a. ed., edición de José Luis Martínez, México, Fondo de Cultura Económica, 1990. 848 p. 
LÓPEZ VELARDE, Ramón, Zozobra, México, Imprenta de Murguía, 1919. (Biblioteca de autores mexicanos modernos, 5)

PACHECO, José Emilio, Antología del Modernismo 1884-1921, 2 tomos, 1a. reimp., México, UNAM, 1978. (Biblioteca del Estudiante Universitario, 90 y 91)

\section{NOTAS}

1. Carmen de la Fuente, López Velarde: su mundo intelectual y afectivo, México Gob. del Edo. de Zacatecas, UAZ, INBA, 1988, p.56.

2. Marshall Berman, Todo lo sólido se desvanece en el aire. La experiencia de la modernidad, México, Siglo XXI, 1989.

3. Ibidem, p.1

4. Ibidem, p. 2

5. Antología del modernismo, 1884-1921, selección, introducción y notas de José Emilio Pacheco, 2 tomos,México, UNAM, 1978. Tomo I, p. XIX

6. Ibidem, pp. XIX-XX.

7. Ibidem, p. XI

8. Max Henríquez Ureña, Breve historia del modernismo, 1954. Citado en Ibidem, p. XIV.

9. Ibidem, p. XVIII.

10. Carmen de la Fuente, op.cit., p.56. Cabe mencionar que para José E. Pacheco, López Velarde no representa un poeta posmodernista como señala De la Fuente, sino que es el poeta que cierra la estación del modernismo, es el último de los poetas modernistas. Vid. Antología..., pp. L-LI.

11. Gustavo Garza V., El proceso de industrialización en la ciudad de México 1821-1970, México, El Colegio de México, 1985, p.109-117.

12. El consumo de electricidad se extendió a la fabricación de prácticamente todo tipo de productos: materiales de construcción, cigarros y puros, productos de hierro y acero, ladrillos, hielo, jabón, llantas de automóvil, zapatos, muebles, productos químicos, harinas, hule, alcoholes y cerveza. Gustavo Garza, op. cit., p. 121.

13. Sobre el financiamiento de las obras públicas en la ciudad de México durante el porfiriato véase mi trabajo Sergio Miranda P., "El financiamiento de las obras públicas en la ciudad de México, 1896-1903”, en María E. Romero y José M. Contreras, Poder público y poder privado. Gobiernos, empresarios y empresas 1880-1980, México, Facultad de Economía, UNAM, 2006, pp.

14. Julieta Ortiz Gaitán, "Mandatos seductores: publicidad y consumo como símbolo de modernidad en la ciudad de México (1900-1930)", en María del C. Collado (coord.), La ciudad de México en los siglos XIX y XX, 2 vols., México, Instituto Mora/UAM-Azcapotzalco, 2004, vol. 1, pp. 84-101

15. José Juan Tablada, "Vida Metropolitana", El Mundo Ilustrado, México, 1 de enero de 1907. Citado en Julieta Ortiz Gaitán, "Mandatos seductores: publicidad y consumo como símbolo de modernidad en la ciudad de México (1900-1930)”, en María del C. Collado (coord.), La ciudad de México en los siglos XIX y XX, 2 vols., México, Instituto Mora/UAM-Azcapotzalco, 2004, vol. 1, p. 90. Para un estudio sobre las imágenes del progreso material y la moral e ideología del Porfiriato vid. Claudia Agostoni, Monuments of Progress. Modernization and Public Health in Mexico City, 1876-1910, University of Calgary Press/University Press of Colorado/Instituto de Investigaciones Históricas de la UNAM, 2003.

16. Erika Berra Stoppa, La expansión de la ciudad de México y los conflictos urbanos, 1900-1930, 2 vols., México, El Colegio de México, 1982 (Tesis Dr. en Historia), tomo I, pp. 88-89. 
17. Guillermo Sheridan cuenta que el mismo López Velarde empleó el teléfono para asediar a la dama de los guantes negros, Margarita Quijano. Vid. Guillermo Sheridan, Un corazón adicto: la vida de Ramón López Velarde, México, FCE, 1989.

18. Julieta Ortiz, op. cit. p. 86.

19. Club Nacional de México Parque Lira, Tacubaya, D.F. s.p.i. Folleto publicitario.

20. Julio Sesto, La ciudad de los palacios (c.1917), citado en Mauricio Tenorio Trillo, El urbanista, México, Fondo de Cultura Económica, 2004, p. 215.

21. Testimonio de Evelyn Trent, nacida en 1892 en Salt Lake City, Estados Unidos, quien vivió en la ciudad de México entre 1918 y 1920, junto con el que era entonces su esposo M.N. Roy, nacido en la India, personaje misterioso vinculado al comunismo internacional (México, China, Alemania e India) y representante mexicano en el segundo Congreso del Comintern en Moscú. Citado en Tenorio Trillo, op. cit. p. 71.

22. Ramón López Velarde, Obras, 2a. ed., edición de José Luis Martínez, México, Fondo de Cultura Económica, 1990, p. 122.

23. Ibidem, pp. 144-145.

24. Ibidem, pp. 146-147.

25. Ibidem, pp. 151-155.

26. Ibidem, p. 125

27. Ibidem, p. 142.

28. Ibidem, p. 165.

29. Ibidem, p. 187.

30. Guillermo Sheridan, Un corazón adicto: la vida de Ramón López Velarde, México, FCE, 1989, p. 177. Son varios los espacios de su obra en prosa que dedica a criticar la moderna forma de vivir presente en la ciudad de México. Veáse, por ejemplo, su espléndido ensayo El alquiler de la vida y la muerte, en el que critica que actos tan íntimos del hombre, como el casarse y el morirse, sean sujetos de mercadeo y de hipocresía social. En Novedad de la patria inquiere sobre el futuro de las ciudades de nuestro país que entonces eran escenario permanente de la violencia, según sugiere él.

31. En el poema El Candil, fechado en 1928, Velarde escribe: 'Candil, que vas como yo enfermo de lo absoluto [...]'

32. En otro poema, La Tejedora, fechado c. 1925, leemos: 'Divago entre quimeras difuntas y entre sueños nacientes, y propenso a un llanto sin motivo, voy, con el alma dispersa [...]'

\section{RESÚMENES}

El presente ensayo se propone demostrar la zozobra moral que provocó en Ramón López Velarde (1888-1921) la vida moderna de la ciudad de México en la que vivió durante los últimos seis años de su vida. A través de un breve examen de las transformaciones urbanas de la ciudad de México de esos años, de las relaciones entre la modernidad urbana y la literatura, de textos críticos de su obra y, principalmente, del análisis de su poesía, más que de su prosa, se muestran y explican las experiencias urbanas retratadas en su poesía, y se destaca el carácter moral y contradictorio de éstas, como un rasgo tanto de su poesía como de la experiencia de la modernidad urbana de México de las primeras décadas del siglo XX. 
Le texte de cet essai propose de montrer l'angoisse morale que la vie moderne de Mexico a provoqué chez Ramón Lopez Velarde (1888-1921) au cours des six dernières années de sa vie. Á travers une brève analyse des transformations urbaines de la ville de Mexico durant ces années, des relations entre modernité urbaine et littérature, des textes critiques sur son œuvre, et surtout, de l'analyse de sa poésie plus que de sa prose, nous montrerons et expliquerons les expériences urbaines décrites dans sa poésie. Nous mettrons l'accent sur le caractère moral et contradictoire de ces dernières, en l'envisageant comme un trait autant de sa poésie que de l'expérience de la modernité urbaine de Mexico dans les premières décades du vingtième siècle.

\section{ÍNDICE}

Palabras claves: Ramón López Velarde, Ciudad de México, siglo XX, modernidad, poesía, experiencia urbana

\section{AUTOR}

\section{SERGIO MIRANDA PACHECO}

Historiador, Instituto de Investigaciones Históricas, Universidad Nacional Autónoma de México 